Research Article

\title{
Aspirin in Food Samples for Separation and Micro Determination of Copper(II) Using Cloud Point Extraction/Solvation Method
}

\author{
Ebaa Adnan Azooz ${ }^{1}$, Jihan Razzaq Moslim², Safa Mageed Hameed ${ }^{2}$, Shawket Kadhem Jawad², \\ Emad Abbas Jaffar Al-Mulla ${ }^{3}$ \\ ${ }^{1}$ The Gifted Students' School in Najaf. The General Directorate of Education Al-Najaf, Ministry of Education, Iraq. \\ ${ }^{2}$ Chemistry Department, Faculty of Education for Women, University of Kufa, Al-Najaf, Iraq. \\ ${ }^{3}$ Pathological Analysis Techniques, Faculty of Health and Medical Techniques, Al-Furat Al-Awsat Technical University, An-Najaf, \\ Iraq. \\ Corresponding authors. E-mail: Ebaaadnan.ed12p@uokufa.edu.iq; almullaemad@gmail.com
}

Received: Jun. 16, 2020; Accepted: Oct. 27, 2020; Published: Jan. 20, 202I

Citation: Ebaa Adnan Azooz, Jihan Razzaq Moslim, Safa Mageed Hameed, Shawket Kadhem Jawad, and Emad Abbas Jaffar Al-Mulla,Aspirin in Food Samples for Separation and Micro Determination of Copper(II) Using Cloud Point Extraction/Solvation Method. Nano Biomed. Eng., 202 I, I3(I): 62-71.

DOI: 10.5101/nbe.v13i1.p62-71.

\begin{abstract}
In this work, sensitive method was used for the first time by joining cloud point extraction with solvation system (CPE-SS) using aspirin as the organic reagent to form cloud point layer (CPL). It had a wavelength for final absorbance under $\lambda_{\max }=293 \mathrm{~nm}$. Different kinds and concentrations of salting out with different extraction efficiencies were used to enhance the extraction efficiency. $\mathrm{KNO}_{3}$ as a salting out under $0.1 \mathrm{M}$ showed maximum extraction efficiency in the presence of $40 \mu \mathrm{g}$ of $\mathrm{Cu}(\mathrm{II})$. The applications of extraction in this method had required the existence of $0.4 \mathrm{~mL}$ of Triton X-100 and heating under $85^{\circ} \mathrm{C}$ for 20 minutes to form CPL quantitatively. The effect of different surfactants and various organic reagents to investigate the impact of interferences as well as spectrophotometric determination were also investigated in this study. Chicken, breast, cow meat (beef), cucumber, drainage fish, garden cress and lettuce showed low limit of detection (LOD) 0.018 ppm, limit of quantity (LOQ) $0.060 \mathrm{ppm}$ and RSD\% of 0.028 in $2 \mathrm{ppm}$.
\end{abstract}

Keywords: Aspirin, Cloud point extraction, Copper, Solvent extraction, Separation

\section{Introduction}

Copper is very necessary for the activity of several enzymes. Copper and iron partially require for hematopoiesis for the reason that it is required for ferroxidase (ceruloplasmin) synthesis. In biological systems, copper has an oxidation state of (I or II). The copper quantity in the adult humanoid body is about 70-100 mg. The maximum concentrations in increasing sequence are in the kidney, heart, brain, and liver.
About $50 \%$ of total copper are found in Muscle. It is absorbed from food in the upper small intestine [1-4].

Aspirin (acetylsalicylic acid) is among the cheaper and most available medicines widely used over the entire world for relief of headaches, heat and muscular pains. Salicylate drug can be in effect in lessening the risk of numerous cancers, especially in lung and colon by its functions as an antioxidant and capability to extremists $[5,6]$.

Different techniques were examined for copper pre- 
concentration and separation in different environmental and organic matrices. Methods as solvent micro extraction [7, 8], also used another ion [9], solid phase extraction (SPE) [10], inductively coupled plasma mass spectrometry [11], ion chromatography [12], flame and graphite furnace atomic absorbing spectrometry [13] and spectrophotometric methods [14-15] and cloud point extraction (CPE) [16], [17] were described for this purpose. Nevertheless, extraction methods such as LLME or SPE, have most amounts of biological solvent that are particularly toxic volatile, flammable and destructive to the surroundings [18], or large volumes of eluents to guarantee the whole backextraction of the interested analytes, correspondingly. CPE has appeared as an in effect, sensitive and greener alternative to LLME and SPE [19].

$\mathrm{CPE}$ is in general performed by means of solutions of a solitary or a combination of surfactants beyond their critical micelle concentrations (CMC). According to the CPE process of the analytes into the micelle layer, conforming can be obtained by intensifying the temperature beyond the critical temperature (CT). This increased temperature causes the cloud point layer (CPL) formation that is the dehydration consequence of the polar surface of the micelles. It produces a good potential amid micelles. The CPL can be categorized by a smaller volume as compared with the one of the aqueous sample in which preconcentration the analytes of interest [20-22]. Many researchers have reported that successful CPE to separate and determine $\mathrm{Cu}$ and other elements in different real samples such as food CPE coupled with flame atomic absorption spectrometry [23] and water combined with ICP-MS [24], by using many surfactants.

Amoxicillin can be applied as a ligand to the determine copper(II) by CPE joined with spectrofluorometric in the presence of Triton X-114 as the surfactant [25]. Applied to extract $\mathrm{Cu}, \mathrm{Co}$ and $\mathrm{Ni}$ in water testers using 2-(5-bromo-2-pyridylazo)-5(diethyl amino) phenol (5-Br-PADAP) as ligand and Triton X-114 [26]. The study indicates that the CPE has excellent potential in Nano-materials removal from wastewater Triton X-114 suitable for the recovery of Nano sized Copper oxide (NCO) from the water. Removing process of $\mathrm{NCO}$ has been affected by the concentrations of Triton $\mathrm{X}-114$ and salt, solution $\mathrm{pH}$ as well as incubation temperature and time [27].

In successful studies, coupled CPE with other extraction method such as solvation method (CPE-SS) was used to extract and determine Ce(III) salting out of $\mathrm{KNO}_{3}$ by means of organic reagent 2,4-Dimethyl pentane-3-one (2,4-DMP) as extractant and 1\% Triton $\mathrm{X}-100$ [28]. Or onium system (CPE-OS) that used to separate and determine micro amount of iron and mercury by means of $\mathrm{N} \alpha$-Benzoyl-L-arginine ethyl ester hydrochloride (BAEE) from acidic hydrochloric aqueous solution as extractant and non-ionic surfactant $1 \%$ Triton $\mathrm{X}-100$. This procedure has low detection limit [29], and liquid-liquid extraction (CPE-LLE) procedure combined with CPE for the extraction trace amount of ions such $\mathrm{Ni}(\mathrm{II})$ [30] and $\mathrm{Cu}(\mathrm{II})$ in drinking water and serum samples. This method is related to ionic liquid assisted micro emulsion (IL- $\mu$ E-DLLME) by means of ionic liquid 1-butyl-3-methylimidazolium hexafluorophosphate ([C4mim] [PF6]). Copper has been reacted with 8 -hydroxyquinoline and Triton $\mathrm{X}-100$ as the surfactant [31].

In this work, a sensitive CPE-SS technique has employed the water as the solvents without using any amounts of the organic solvents for feasible using surfactants in analytical chemistry. Instantaneous determination and preconcentration of $\mathrm{Cu}$ (II) using aspirin as a selective complexing agent and Triton $\mathrm{X}-100$ were investigated.

\section{Experimental Materials}

All chemicals used in this study were from Merck, Germany. Standard solution was prepared using $1 \mathrm{mg} /$ $\mathrm{mL}$ of $\mathrm{Cu}\left(\mathrm{NO}_{3}\right)_{2}$ in $100 \mathrm{~mL}$ of distilled water. The solution aspirin ligand was prepared in distilled water with Triton X-100 as a surfactant.

\section{Instruments}

A double beam Biochrom spectrophotometer with $1.00 \mathrm{~cm}$ quartz cell and WNB7-45 water bath were used for spectroscopic studies and CPT heating along, Dool, CE, HR 200, Japan.

\section{Preparation of samples}

All samples under study were taken from local supermarkets and different places of Euphrates river, An-Najaf, Iraq. A $5 \mathrm{~g}$ of a dried sample was places in a $200 \mathrm{~mL}$ conical flask with $10 \mathrm{~mL}$ of concentrated nitric acid. The mixture was heated at $70{ }^{\circ} \mathrm{C}$ for 20 min, cooled and then another of $10 \mathrm{~mL}$ of concentrated nitric acid, $5 \mathrm{~mL}$ of concentration sulpheric acid and $4 \mathrm{~mL}$ hydrogen peroxide were added. After that, the mixture was mixed with a magnetic stirrer and reheated at $85^{\circ} \mathrm{C}$ for $20 \mathrm{~min}$, then $10 \mathrm{~mL}$ of water was added 
till it is colorless indicate that organic matter oxidation. A $100 \mathrm{~mL}$ volumetric flask was used to transfer the cooled product with adding distilled water to the mark. A $5 \mathrm{~mL}$ of final product was diluted with distilled water to $25 \mathrm{~mL}$ conical flask, then added $1 \mathrm{~mL}$ of $20 \%$ potassium sodium tartrate. The mixture was filtered and transferred to $10 \mathrm{~mL}$ volumetric flask and added distilled water for diluting to the mark.

\section{General method}

Aqueous solutions (10 mL each) in volume have the finest quantity of $\mathrm{Cu}$ (II) and optimal concentration of $\mathrm{KNO}_{3}$ as salting out with $1 \times 10^{-4} \mathrm{M}$ of aspirin in the existence suitable volume of surfactant. The solutions heated in a water bath for relevant temperature, time of heating up to cloud point layer (CPL) realization. The absorption of a solvation species is determined at $\lambda_{\max }=293 \mathrm{~nm}$. Nonetheless, the aqueous solution has been handled along with dithiazone spectrophotometric process. Then, go back to the calibration curve with the purpose of determination the remainder amount of $\mathrm{Cu}(\mathrm{II})$ in aqueous phase next to extraction. Afterward, subtract from $(40 \mu \mathrm{g})$ to evaluate the transferred quantity of Copper into CPL as solvation species. Subsequently, compute distribution ratio (D) in relation to Equation (1)

$\mathrm{D}=([\mathrm{Cu}(\mathrm{II})] \mathrm{CPL}) /([\mathrm{Cu}(\mathrm{II})] \mathrm{aq})$.

\section{Results and Discussion}

The spectrophotometric study shows that solvation species of $\mathrm{Cu}$ (II) with Aspirin extracted into CPL have a wavelength of maximum absorbance equal to of 293 nm (Fig. 1).
Factors influencing extraction efficiency Type and concentration of salting out

Each sample of aqueous solutions $(10 \mathrm{~mL})$ was used in volume comprises $(50 \mu \mathrm{g})$ of $\mathrm{Cu}(\mathrm{II})$ and increasing concentration of different salting out levels in existence of $0.5 \mathrm{~mL}$ of $1 \%$ Triton $\mathrm{X}-100,1 \times 10^{-4} \mathrm{M}$ of aspirin, the solutions has been heated for appropriate temperature and period up to CPL formation. At that point, separated CPL and stream CPL in $5 \mathrm{~mL}$ of alcohol. $\lambda_{\max }=293 \mathrm{~nm}$ was appeared for alcoholic absorption against blank without $\mathrm{Cu}(\mathrm{II})$ prepared in the same manner. Aqueous phase has treated concerning dithiazone spectrophotometric method consistent with general technique. The consequences have been depicted in Figs. 2 and 3.

The best concentration was evidenced at $0.1 \mathrm{M}$ for all salting out levels that given higher extraction efficiency of $\mathrm{Cu}(\mathrm{II})$ as solvation species with aspirin. That emphasizes the role of kind and concentration salting out on extraction efficiency. They are considered as a thermodynamic factor and control the rate of formation of solvation species.

\section{Copper concentration}

A $10 \mathrm{~mL}$ of each sample in $\mathrm{Cu}(\mathrm{II})$ and $0.1 \mathrm{M}$ of $\mathrm{KNO}_{3}$ as salting were used in the presence of $1 \times 10^{-4} \mathrm{M}$ of aspirin and $0.5 \mathrm{~mL}$ of surfactant. Electrostatic water bath was used to heat the solutions at $85^{\circ} \mathrm{C}$ and for $20 \mathrm{~min}$. Accomplish the experiment in line with the general process. The outcomes have been clarified in Figs. 4 and 5.

As shown in Figs. 4 and 5, there is a linear relationship within the concentration of $\mathrm{Cu}(\mathrm{II})$ and extraction efficiency until optimal concentration

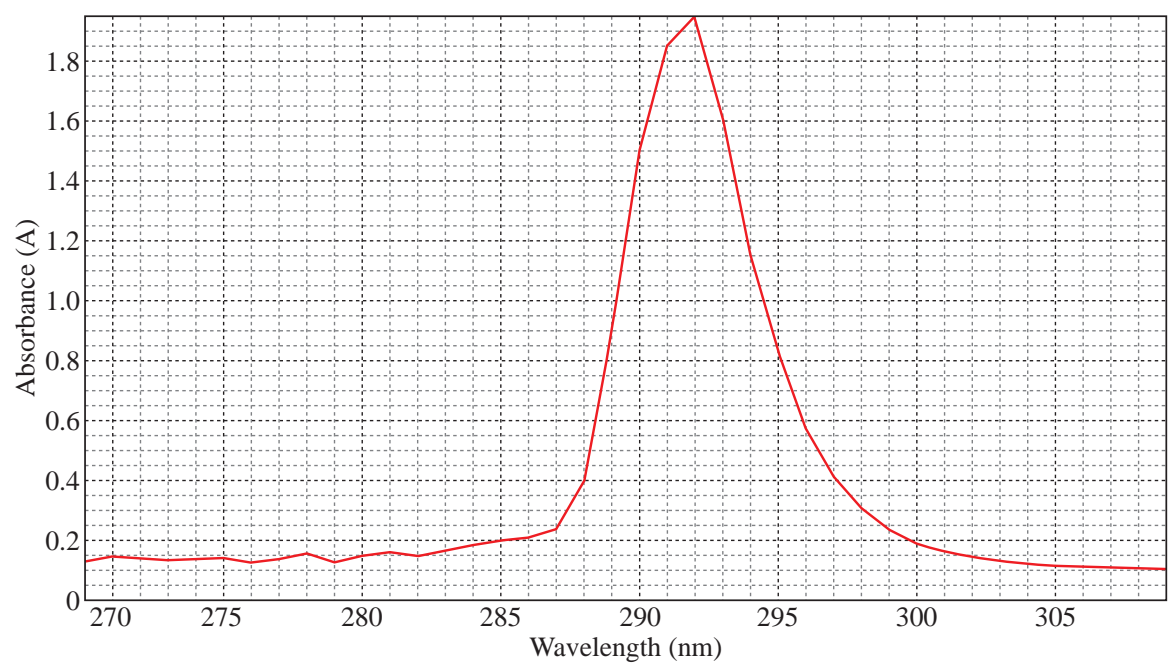

Fig. 1 UV-Vis absorption spectrum of solvation species of $\mathrm{Cu}(\mathrm{II})$ with aspirin. 


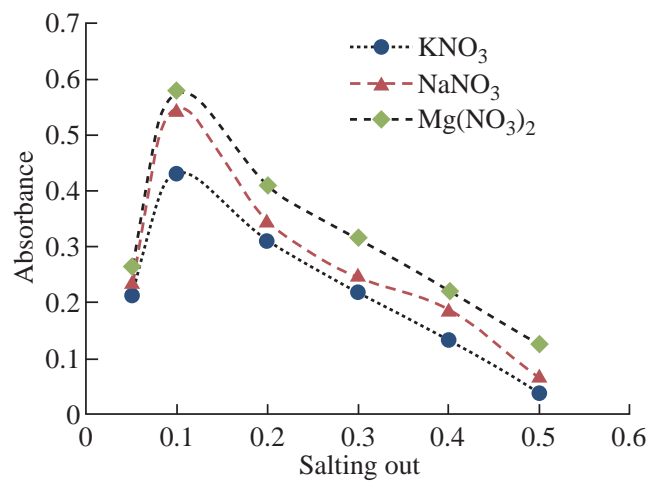

Fig. 2 Effect of type and concentration of salting out on formation solvation species of $\mathrm{Cu}(\mathrm{II})$.

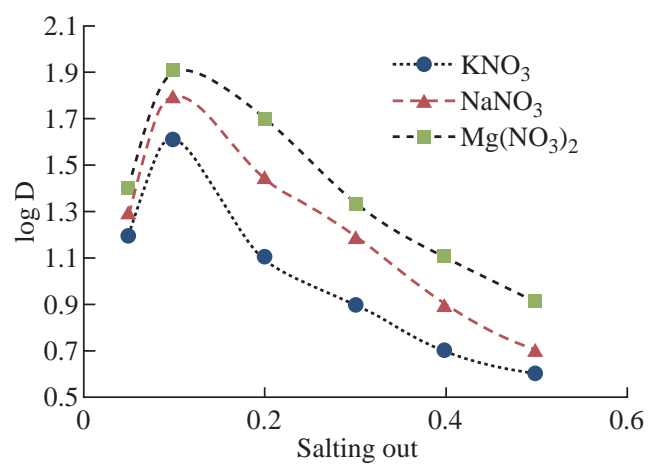

Fig. 3 Effect of type and concentration of salting out on extraction efficiency of $\mathrm{Cu}$ (II) and D-value.

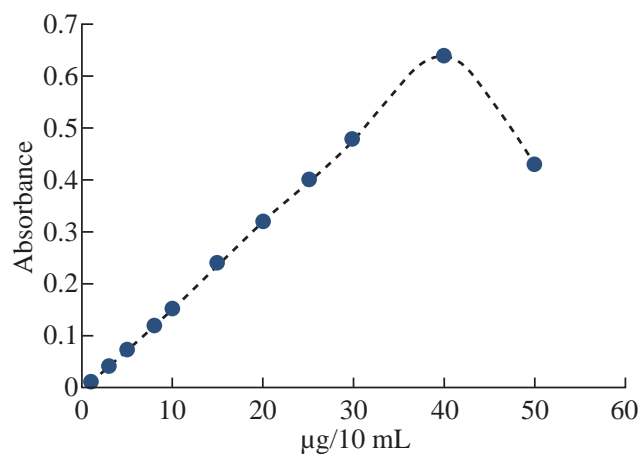

Fig. 4 Effect of $\mathrm{Cu}(\mathrm{II})$ concentration on stability of solvation species.

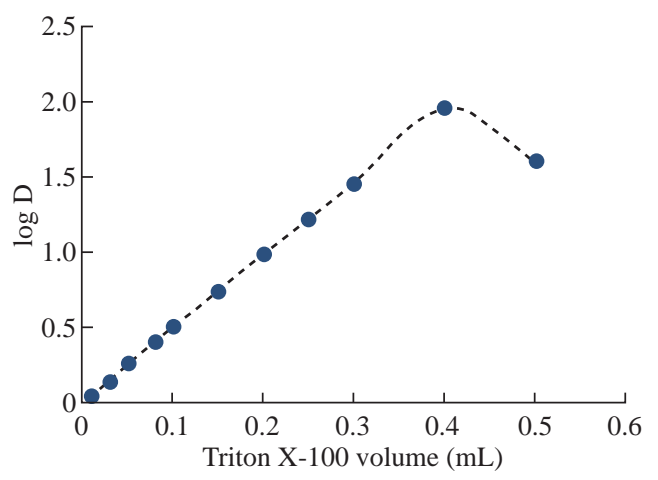

Fig. 5 Effect of $\mathrm{Cu}(\mathrm{II})$ concentration on D-values.

$40 \mu \mathrm{g} / \mathrm{mL}$ that gives greater efficiency. Increasing in concentration of $\mathrm{Cu}(\mathrm{II})$ gives an intensification in the rate of formation of solvation species. More concentration than optimal magnitude has effects of diminishing extraction efficiency because it raises the rate of backward direction of thermodynamic steadiness and lessens solvation species formation concerning mass action law.

\section{Surfactant volume}

By following general method, the absorbance curves of $40 \mu \mathrm{g}$ of $\mathrm{Cu}$ (II) in $10 \mathrm{~mL}$ in aqueous solutions in existence of $1 \times 10^{-4} \mathrm{M}$ of aspirin and $0.1 \mathrm{M}$ of $\mathrm{KNO}_{3}$ as salting out with increasing volumes of $1 \%$ Triton $\mathrm{X}-100$ as a surfactant were shown in Figs. 6 and 7 . Higher extraction efficiency was observed with finest surfactant volume $(0.4 \mathrm{~mL})$ which accomplishes our status of analytical micelles concentration CMC to create the finest CPL with the finest features to extract solvation species quantitatively. Any volume less than the finest level was not tolerable for CMC to facilitate any volume more than optimum volume effect of dropping extraction efficiency since declining CPL properties is in effect of diffusion of micelles.

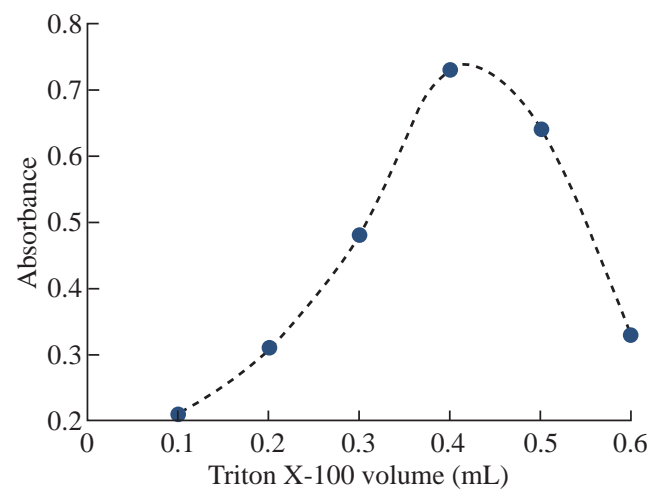

Fig. 6 Effect of surfactant volume on formation CPL with best properties.

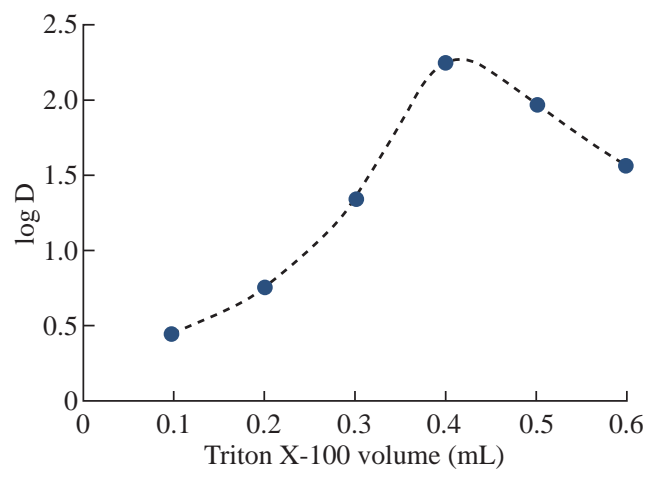

Fig. 7 Effect of surfactant volume on extraction efficiency and D-values.

\section{Temperature}

The general method was applied to determine the rising temperature for $\mathrm{Cu}(\mathrm{II})$. The absorbance 
consequences are shown in Figs. 8 and 9.

Afterword, extraction constant $\left(\mathrm{K}_{\mathrm{ex}}\right)$ is possibly calculated in relation to equation (2). The results were as in Fig. 12.

$\mathrm{K}_{\mathrm{ex}}=\mathrm{D} /([\mathrm{Cu}(\mathrm{II})][$ aspirin $])$.

The results of thermodynamic data for extraction Cu(II) according a straight slope line (Fig. 10) and relations of thermodynamic (Table 1 ). They were shown formation solvation species with endothermic reaction. The low value of enthalpy of extraction $\left(\Delta \mathrm{H}_{\mathrm{ex}}\right.$ with good binding for solvation species with high

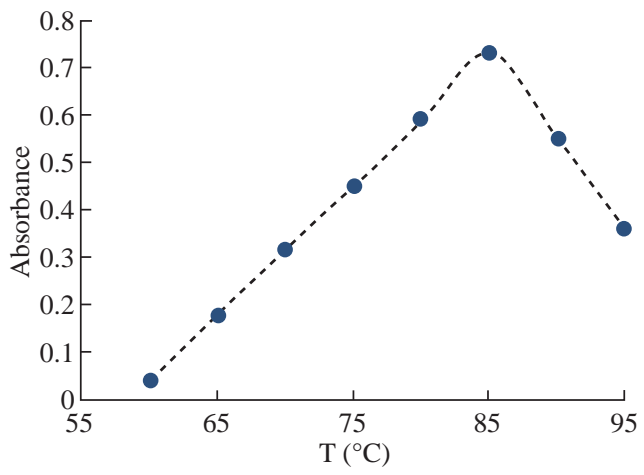

Fig. 8 Effect of temperature on formation CPL.

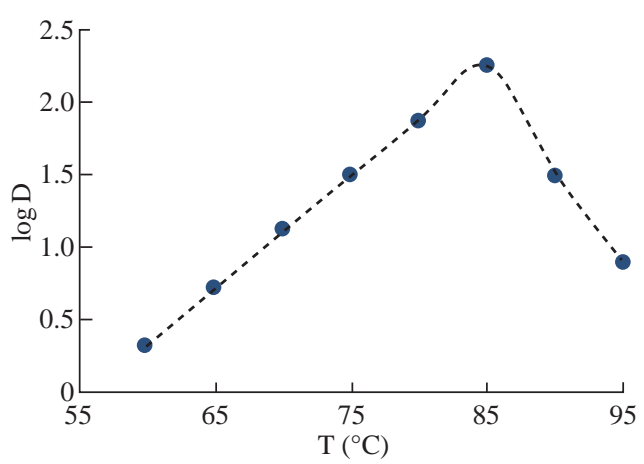

Fig. 9 Effect of temperature on extraction and D-values.

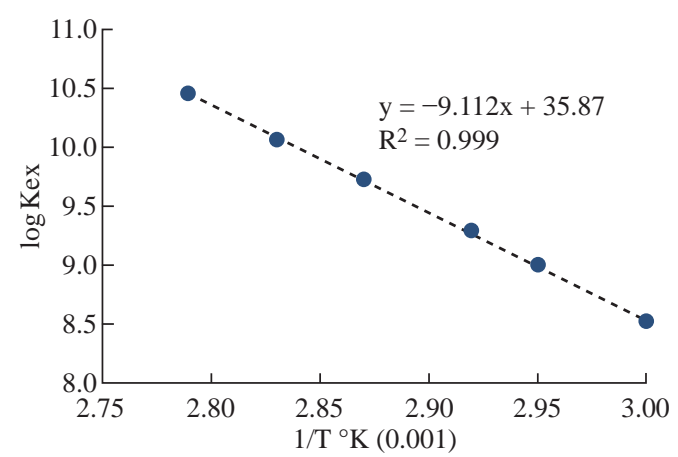

Fig. 10 Temperature based on extraction constant of $\mathrm{Cu}(\mathrm{II})$ in solvation species.

Table 1 Thermodynamic data for extraction $\mathrm{Cu}(\mathrm{II})$ according to applied method CPE

\begin{tabular}{ccc}
\hline$\Delta \mathrm{H}_{\mathrm{ex}}(\mathrm{KJ} / \mathrm{mole})$ & $\Delta \mathrm{G}_{\mathrm{ex}}(\mathrm{KJ} /$ mole $)$ & $\Delta \mathrm{S}_{\text {ex }}(\mathrm{J} /$ mole. $\mathrm{K})$ \\
\hline 0.1759 & -71.625 & 200.000 \\
\hline
\end{tabular}

stability were observed. Nevertheless, the high value of entropy of extraction $\left(\Delta \mathrm{S}_{\mathrm{ex}}\right)$ demonstrates that the extraction method depends on entropy in the formation of solvation species.

\section{Heating time}

Each sample of aqueous solutions $(10 \mathrm{~mL})$ was at the optimum condition of $40 \mu \mathrm{g}$ of $\mathrm{Cu}$ (II) in different heating times. The absorbance results were shown in Figs. 11 and 12. It was observed that the most likely heating time was $20 \mathrm{~min}$. Heating period stands for the kinetic side of extraction provides the necessary energy for aggregation micelles with proper dehydration. More time in optimal value increases micelles diffusion and decreases extraction efficiency.

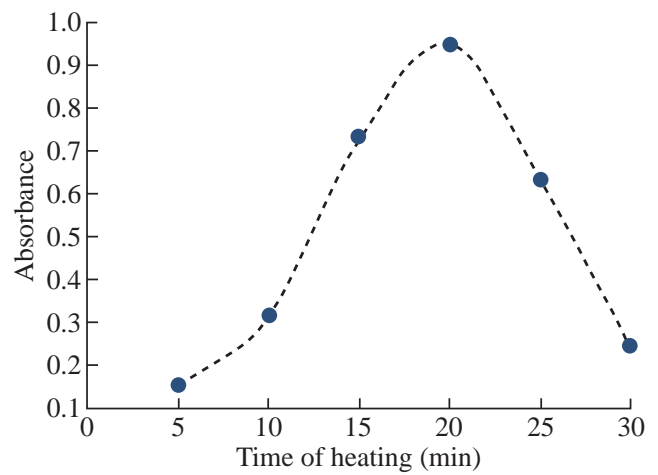

Fig. 11 Relation of heating time and formation of CPL.

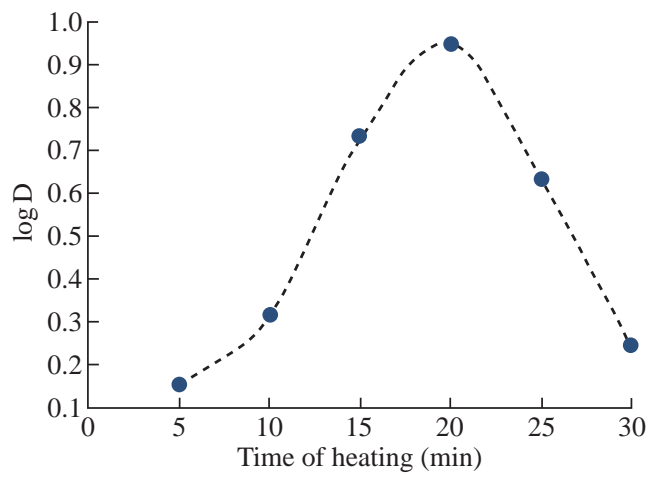

Fig. 12 Heating time with D- values.

\section{Effect of surfactant kind}

Each sample of aqueous solutions $(10 \mathrm{~mL})$ was at the optimum condition of $40 \mu \mathrm{g}$ of $\mathrm{Cu}(\mathrm{II}), 0.1 \mathrm{M}$ of $\mathrm{KNO}_{3}, 1 \times 10^{-4} \mathrm{M}$ of aspirin and $0.5 \mathrm{~mL}$ of different surfactants. The results reveal that there was a significant relationship between surfactant kind and extraction efficiency that used tweens appear lower in Distribution ratio (D). Different surfactants give different CPL with different features and various extraction efficiencies to be different in micelles structure as well as each surfactant needs special 
conditions to form CPL. Tween-40 gives high D value that may use in other studies after controlled conditions reaction.

\section{Effect of organic reagent}

The sample $(10 \mathrm{~mL})$ was treated at optimum condition of $40 \mu \mathrm{g}$ of $\mathrm{Cu}(\mathrm{II}), 0.1 \mathrm{M} \mathrm{KNO}_{3}, 0.4 \mathrm{~mL}$ of surfactant Triton X-100 and $1 \times 10^{-4} \mathrm{M}$ of different organic reagents. The results were in Table 3. It was illustrated that organic reagent was very imperative in the formation of solvation species. Different absorbance and D-values with different organic reagents with new solvation species were observed. It

Table 2 Effect of surfactant kind on extraction efficiency of $\mathrm{Cu}(\mathrm{II})$ according to solvation system

\begin{tabular}{ccc}
\hline Surfactant & Absorbance $\lambda_{\max }=293 \mathrm{~nm}$ & Distribution ratio (D) \\
\hline Tween-40 & 0.410 & 85.670 \\
Tween-20 & 0.310 & 72.430 \\
Tween-80 & 0.222 & 31.57 \\
\hline
\end{tabular}

Table 3 Effect of organic reagents on extraction efficiency of $\mathrm{Cu}(\mathrm{II})$ according to solvation system

\begin{tabular}{cccc}
\hline Organic reagent & $\lambda_{\max }(\mathrm{nm})$ & Absorbance & $\mathrm{D}$ \\
\hline Tributyle phosphate (TBP) & 291 & 1.701 & 65.160 \\
BAEE & 292 & 1.850 & 72.720 \\
Aspirin & 293 & 1.951 & 91.200 \\
Rhodamine 6-G & 555 & 2.308 & 180.740 \\
\hline
\end{tabular}

has a specific wavelength for maximum absorbance with $\lambda_{\max }=293 \mathrm{~nm}$ so that each organic reagent needs special conditions to form solvation species. The depictions of the spectrum for each organic reagents were shown in Figs. 13-15.

\section{Interferences effect}

All samples contain $40 \mu \mathrm{g}$ of $\mathrm{Cu}(\mathrm{II}), 0.1 \mathrm{M}$ of $\mathrm{KNO}_{3,} 0.4 \mathrm{~mL}$ of surfactant Triton X-100 and $1 \times 10^{-4} \mathrm{M}$ of aspirin as organic reagents in existence of $0.01 \mathrm{M}$ of different foreign metal cations in $10 \mathrm{~mL}$ solution. The wavelength for maximum absorbance was with $\lambda_{\max }=$ $293 \mathrm{~nm}$. The results have been summarized in Table 4. It was shown presence of all foreign metal cations in side by side with $\mathrm{Cu}(\mathrm{II})$ to decrease extraction efficiency of $\mathrm{Cu}(\mathrm{II})$. This interferences behavior was because these metal cations participate $\mathrm{Cu}(\mathrm{II})$ in the formation of solvation species. This indicates

Table 4 Effect of interferences on extraction efficiency of $\mathrm{Cu}(\mathrm{II})$ according to solvation system

\begin{tabular}{ccc}
\hline Interferences & Absorbance & Distribution value (D) \\
\hline $\mathrm{Cd}(\mathrm{II})$ & 0.624 & 61.81 \\
$\mathrm{Zn}(\mathrm{II})$ & 0.574 & 58.56 \\
$\mathrm{Ni}(\mathrm{II})$ & 0.486 & 46.33 \\
$\mathrm{Co}(\mathrm{II})$ & 0.741 & 64.42 \\
$\mathrm{~Pb}(\mathrm{II})$ & 0.544 & 62.61 \\
$\mathrm{Hg}(\mathrm{II})$ & 0.422 & 38.27 \\
\hline
\end{tabular}

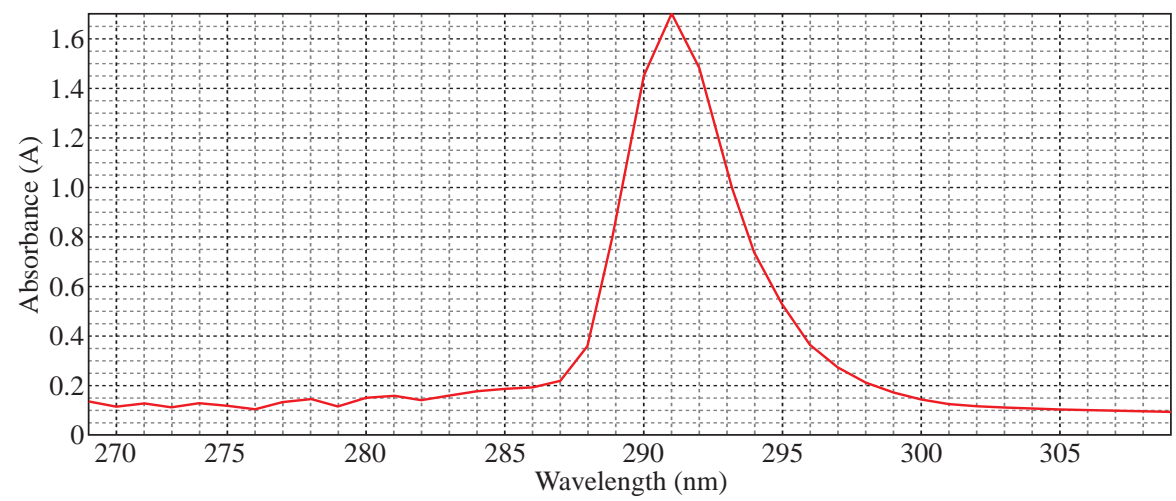

Fig. 13 Solvation method with TBP.

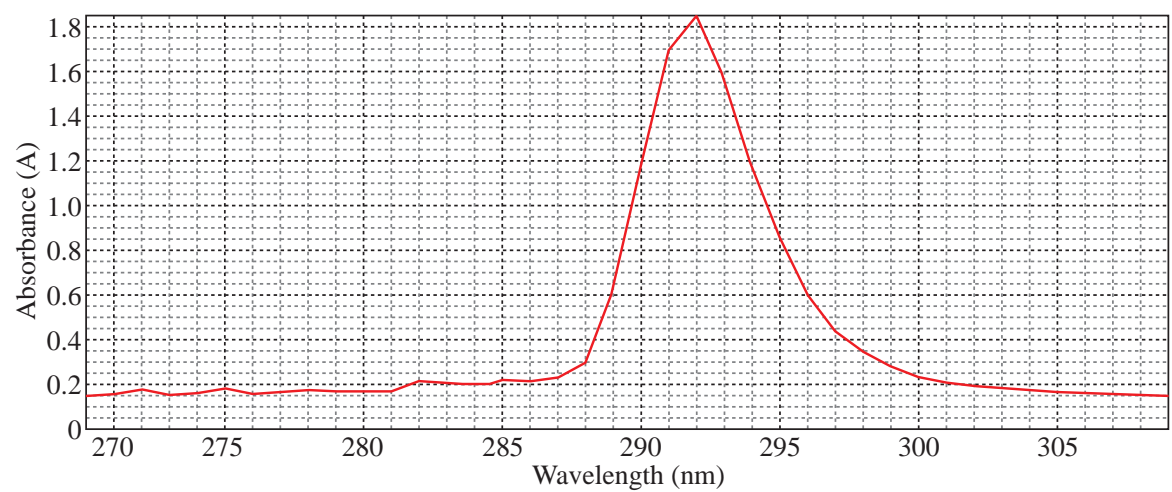

Fig. 14 Solvation method with BAEE. 


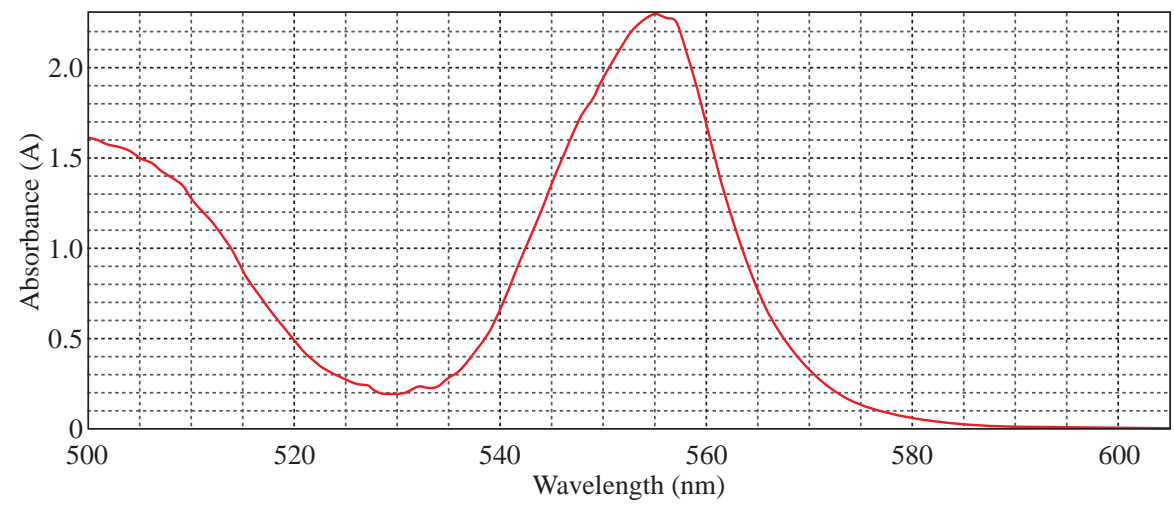

Fig. 15 Solvation method with Rhodamine 6-G.

the consumption of some salting out levels of $\mathrm{KNO}_{3}$ and aspirin. Decreases of the concentration of $\mathrm{KNO}_{3}$ and aspirin down the necessary for the formation of solvation species of $\mathrm{Cu}(\mathrm{II})$ and declines the extraction efficiency of $\mathrm{Cu}$ (II) [32].

\section{Stoichiometry}

In order to know the most likely structure of extracted solvation species into CPL, follow two types of spectrophotometric methods based on slope analysis and slope ratio. The consequences of these two methods were explained in Figs. 16-18. The results illustrated that there is a solitary molecule of aspirin binding with nitrate compound of $\mathrm{Cu}(\mathrm{II})$ [aspirin; $\mathrm{Cu}$ $\left(\mathrm{NO}_{3}\right)_{2}$ ].

\section{Analysis of food samples}

The developed procedure for separation and

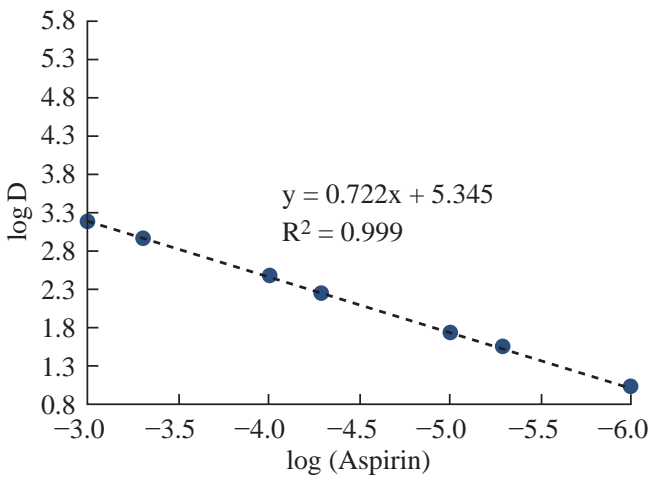

Fig. 16 Slope analysis method. determination of $\mathrm{Cu}(\mathrm{II})$ were from various foods to test its applicability. The masking agents (KI and KF) well be added in $0.01 \mathrm{M}$. The fallouts are explained in Fig. 19. Table 5 has details of the analytical parameters of the calibration curve of this applied method (CPE-SS).

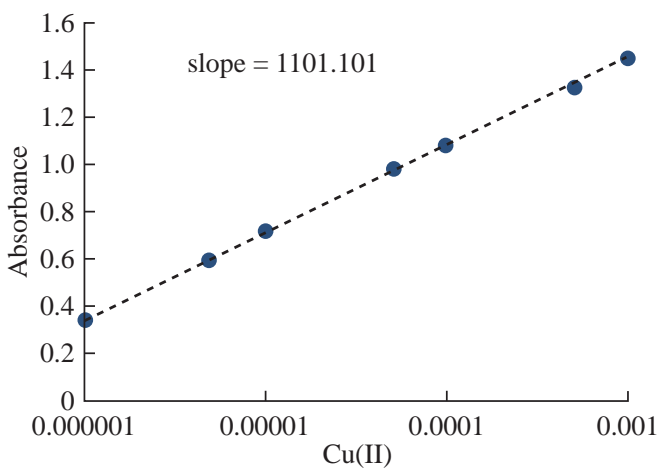

Fig. 17 Slope ratio method effect of $\mathrm{Cu}(\mathrm{II})$ Concentration.

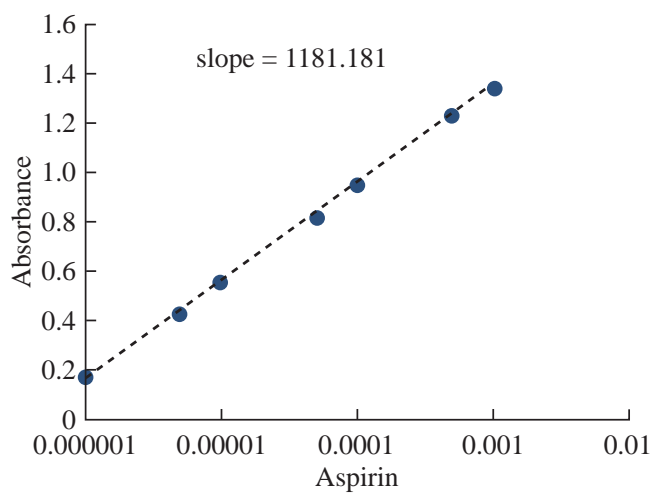

Fig. 18 Slope ratio method effect of aspirin concentration.

Table 5 Method validation of the determination of Cu(II) using CPE procedure according to solvation system

\begin{tabular}{cccc}
\hline Parameter & $\mathrm{Cu}(\mathrm{II})$ & Parameter & $\mathrm{Cu}(\mathrm{II})$ \\
\hline$\lambda_{\max }(\mathrm{nm})$ & 293 & LOD $(\mathrm{ppm})$ & 0.0180 \\
Degree of freedom & 8 & LOQ $(\mathrm{ppm})$ & 0.0600 \\
Determination coefficient $\left(\mathrm{R}^{2}\right)$ & 0.999 & Molar absorptivity $(\mathrm{L} / \mathrm{mol} . \mathrm{cm})$ & 66306.80 \\
$\mathrm{RSD} \%(\mathrm{n}=6$ ) at $2 \mathrm{ppm}$ & 0.028 & Sandell’s sensitivity $\left(\mu \mathrm{g} / \mathrm{cm}^{2}\right)$ & $42 \times 10^{-10}$ \\
Regression equation with extraction & $\mathrm{Y}=0.2382 \mathrm{X}+0.0009$ & Slope & 0.2382 \\
\hline
\end{tabular}


Table 6 gives information regarding amount of $\mathrm{Cu}(\mathrm{II})$ by applied method (CPE-SS) in the food and water

Table 6 Determination of $\mathrm{Cu}(\mathrm{II})$ in real samples according to applied method

\begin{tabular}{ccccc}
\hline No. & Samples & Dithiazone method & Applied method* & RSD $\%$ \\
\hline 1 & Celery & 2.00 & 1.99 & 0.31 \\
2 & Chicken (Breast) & 1.20 & 1.19 & 0.54 \\
3 & Cow meat (Beef) 1 & 0.50 & 0.51 & 0.07 \\
4 & Cow meat (Beef) 2 & 0.60 & 0.56 & 0.12 \\
5 & Cucumber 1 & 3.00 & 3.20 & 0.06 \\
6 & Cucumber 2 & 3.100 & 3.30 & 0.07 \\
7 & Drainage fish & 1.10 & 1.20 & 0.40 \\
8 & Garden Cress & 2.30 & 2.41 & 0.34 \\
9 & Lettuce & 2.80 & 2.79 & 0.02 \\
10 & River water 1 & 0.20 & 0.30 & 0.03 \\
11 & River water 2 & 3.50 & 3.20 & 0.02 \\
12 & Tomato & 1.60 & 1.56 & 0.03 \\
\hline
\end{tabular}

*Values given represent the average of six analyses of each sample

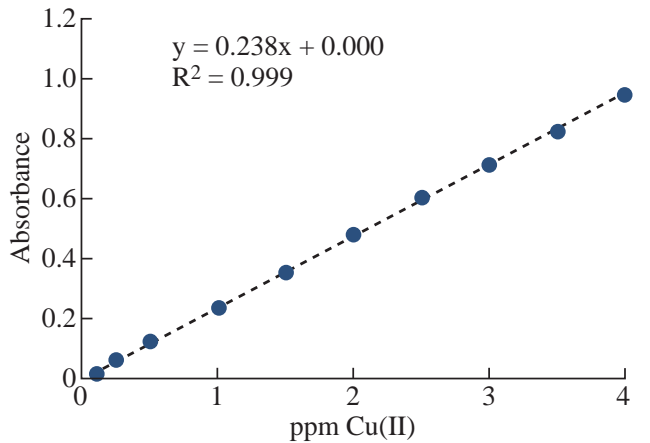

Fig. 19 Calibration curve of applied method to determine $\mathrm{Cu}(\mathrm{II})$ in real samples.

samples [33].

\section{Comparison with other studies}

The applicability of the various methods coupled with CPE was successfully confirmed by separation, preconcentration of tiny $\mathrm{Cu}(\mathrm{II})$ quantity and determination it in water and food testers. Acceptable results are obtained in Table 7.

Table 7 Procedures using cloud point extraction prior copper determination in real samples

\begin{tabular}{|c|c|c|c|c|c|c|c|}
\hline Ligand & Sample volume (mL) & $\mathrm{RSD} \%$ & Samples & Applied method & Surfactant & LOD (ppm) & Ref. \\
\hline Me-BTABr & 10 & 2.6 & water & CPE / FAAS & Triton X-114 & 1.08 & {$[34]$} \\
\hline TAN & 50 & -- & water & CPE / FAAS & Triton X-114 & 0.27 & {$[35]$} \\
\hline O,O-DDTP & 10 & -- & $\begin{array}{l}\text { Drinking and rainwater, } \\
\text { serum and human hair }\end{array}$ & CPE / FAAS & Triton X-100 & 0.94 & {$[36]$} \\
\hline PAN & 10 & -- & $\begin{array}{l}\text { Tap water, snow water, } \\
\text { and flavor wines }\end{array}$ & $\mathrm{CPE} / \mathrm{CE}$ & Triton X-114 & 0.26 & {$[37]$} \\
\hline $\begin{array}{l}\text { A-O,O- } \\
\text { DDTP }\end{array}$ & 40 & -- & $\begin{array}{l}\text { Riverine water, sea water and enriched } \\
\text { water reference materials }\end{array}$ & CPE / ICP-MS & Triton X-114 & 0.03 & {$[38]$} \\
\hline PTU & 15 & 1.4 & Food & CPE / FAAS & Triton X-114 & $1.6 \mathrm{ng} / \mathrm{mL}$ & [39] \\
\hline MPMP & 25 & 1.8 & Rice flour and water samples & CPE-FI / FAAS & Triton X-114 & 0.15 & {$[40]$} \\
\hline MPKO & 15 & 1.2 & Food & CPE/ FAAS & Triton X-114 & $1.6 \mathrm{ng} / \mathrm{mL}$ & {$[41]$} \\
\hline BDAP & 10 & -- & $\begin{array}{l}\text { Apple leaves, spinach leaves } \\
\text { and tomato leaves }\end{array}$ & CPE/ FAAS & Triton X-114 & 0.1 & {$[42]$} \\
\hline IYPMI & 15 & 2.7 & Food & CPE/ FAAS & Triton X-100 & $1.6 \mathrm{ng} / \mathrm{mL}$ & {$[43]$} \\
\hline NDTT & 10 & 2.1 & Water & CPE/ FAAS & Triton X-114 & $0.22 \mathrm{ng} / \mathrm{mL}$ & {$[44]$} \\
\hline Aspirin & 10 & 0.028 & Food & CPE/Uv-Vis & Triton X-100 & 0.018 & $\begin{array}{l}\text { this } \\
\text { work }\end{array}$ \\
\hline
\end{tabular}

LOD: limit of detection; TAN: 1-(2-thiazolylazo)-2-naphthol; PAN: 1-(2-pyridylazo)-2-naphthol; O, O-DDTP: O, O-diethyldithiophosphate; A-O, O-DDTP: ammonium O, O-diethyl-dithiophosphate; Me-BTABr: 2-[2'-(6-methylbenzothiazolylazo)]-4-bromophenol; 63Cu; 65Cu; FAAS: Flame Atomic Absorption Spectrometry; ICP-MS: Inductively Coupled Plasma Mass Spectrometry; CE: Capillary Electrophoresis; PTU: 4-hydroxy-2-mercapto-6-propylpyrimidine; MPMP: 2-[(2-mercaptophenylimino) methyl]-phenol; MPKO: methyl-2-pyridylketone oxime; BDAP: 2-(2'-benzothiazolylazo)-5-(N, N-diethyl) aminophenol; IYPMI: 3-((indolin-3-yl) (phenyl) methyl) indoline; NDTT: 6-(2-naphthyl)-2, 3-dihydro-astriazine-3-thione. 


\section{Conclusions}

Aspirin medical reagent has been efficaciously employed to preconcentrate, separate, and determine $\mathrm{Cu}(\mathrm{II})$ utilizing cloud point extraction/solvation system. The method has enhanced the presentation of UV-Vis detection considerably. Aspirin reagent to extract and determinate $\mathrm{Cu}(\mathrm{II})$ through CPE-SS exhibits exciting features were used. The technique was the safest and very cost-effective since it requires lower equipment and running costs and a small amount of surfactant of about $0.4 \mathrm{~mL}$. It also has uncomplicatedness in apparatus with accurateness. Aspirin proved to be encouraging to be applied in preconcentration processes including diverse methods as in solid-phase extraction, and cloud-point extraction/solvation system.

\section{Acknowledgments}

The analysis in the advanced analytical Laboratory of Chemistry Department Faculty of Education for Women University of Kufa is exceedingly acknowledged.

\section{Conflict of Interests}

The authors declare that they have no conflict of interest.

\section{References}

[1] E.A. Azooz, F.A. Wannas, and S.K. Jawad, Developed cloud point extraction coupled with onium system for separation and determination cobalt in biological samples. Research Journal of Pharmacy and Technology, 2021, 14(2): 594-598.

[2] M.M. Radhi, L.A.A. Jawad, Saffron in $\mathrm{KCl}$ mediated by glassy carbon electrode using Cyclic voltammetry. Nano Biomedicine and Engineering, 2018, 10(2): 181-185.

[3] N.A.B. Ibrahim, I.H.T. Al-Karkhi, et al., Synthesis of palm oil-based fatty methylhydrazide. Research on Chemecal Intermediates, 2013, 39(5): 2133-2139.

[4] M. Kaykhaii, E. Ghasemi, Micro-cloud point extraction for preconcentration of aspirin in commercial tablets prior to spectrophotometric determination. Journal of Analytical Chemistry, 2016, 71(8): 844-848.

[5] G. Nafisi, B. Sadeghi, and A.P. Yab, Interaction of aspirin and vitamin $C$ with bovine serum albumin. Journal of Photochemistry and Photobiology. B: Biology, 2011, 105: 198-202.

[6] S.K. Jawad, S.M. Hameed, and S.A. Hussein, With solvent extraction method, and via new organic reagent 2-(Benzo thiozolyl azo)-4,5-diphenyl imidazole for spectrophotometric determination of copper (II) in different samples. Baghdad Science Journal, 2014, 11(1): 147-157.
[7] S. Bahar, R. Zakerian, Determination of copper in human hair and tea samples after dispersive liquid-liquid micro extraction based on solidification of floating organic drop (DLLME-SFO). Journal of Brazilian Chemical Society, 2012, 23(6): 1166-1173.

[8] F.A. Wannas, E.A. Azooz, and S.K. Jawad, Liquid ion exchange with spectrophotometric method for separation and determination W(VI). Journal of Advanced Ressearch And Dynamic Control System, 2019, 11(7): 260-269.

[9] Y. Yamini, A. Tamaddon, Solid-phase extraction and spectrophotometric determination of trace amounts of copper in water samples. Talanta, 1999, 49(1): 119-124.

[10] V. Hrastný, M. Komárek, Copper determination using ICP-MS with hexapole collision cell. Chemical Papers, 2009, 63(5): 512-519.

[11] J. Laghari, Y. Muhammad, and K. Liaquat, Capillary gas chromatographic analysis of pyrrolidine dithiocarbamate metal chelates. Journal of Separation Science, 2007, 30(16): 2727-2732.

[12] A.F. Khudhair, M.K. Hassan, Cloud point extraction and determination of trace iron(III) in urine samples by spectrophotometry and flame atomic absorption spectrometry. Asian Journal of Chemistry, 2017, 29(12): 2725-2733.

[13] J.K. Shawket, R.K. Rana, Cloud point extraction coupled with liquid ion exchange for separation and determination $\mathrm{Mn}(\mathrm{VII})$ in real samples. Research Journal of Pharmacy and Technology, 2019, 12(10): 4861-4866.

[14] E.A. Azooz, J.R. Moslim, and S.K. Jawad, Cloud point extraction methodology for separation, extraction and preconcentration of Mn(VII) coupled with spectroscopy for determination in different samples. Biochemical and Cellular Archives, 2020, 20(1): 2641-2648.

[15] S. Shariati, M. Golshekan, Optimization of cloud point extraction of copper with neocuproine from aqueous solutions using taguchi fractional factorial design. Journal of Analytical Chemistry, 2014, 69(3): 248-301.

[16] M. Ghaedi, E. Niknam, Application of triton X-100 coated poly vinyl chloride as new solid phase for preconcentration of $\mathrm{Fe}^{3+}, \mathrm{Cu}^{2+}$ and $\mathrm{Zn}^{2+}$ ions and their flame atomic absorption spectrometric determinations. Bulletin of the Chemical Society of Ethiopia, 2010, 24(1): 11-20.

[17] S.K. Jawad, S.M. Hameed, and S.A. Hussain, Liquid ion exchange application for micro amount separation and determination of $\mathrm{Ca}(\mathrm{II})$ and $\mathrm{Mg}(\mathrm{II})$ as anions species with EDTA, Orienal Journal of Chemistry, 2017, 33 (5): 2421-2429.

[18] G. Blanchet-Chouinard, D. Larivière, Determination of $\mathrm{Pb}$ in environmental samples after cloud point extraction using crown ether. Talanta, 2018, 179: 300-306.

[19] S.K. Jawad, E.A. Azooz, New approach for separation, extraction and determination of zinc in different samples using cloud-point extraction coupled with spectrophotometry. FIRE Journal of Science and Technology, 2015, 3: 261-273.

[20] J.K. Shawket, M.U. Kadhium, and E.A. Azooz, Separation and spectrophotometric determination of Iron(III) and Mercury(II) via Cloud point extraction with new Azoderivative. Eurasian Journal of Analytical Chemistry, 2018, 13(5): 1-11.

[21] S.K. Jawad, E.A. Azooz, Cloud point extraction method for separation and pre concentration of $\mathrm{Mg}(\mathrm{II})$ as anion coupled with spectrophotometric applications. International Journal of Research in Applied, Natural and Social Sciences, 2015, 1(2): 119-133.

[22] E.A.J. Al-Mulla, K.W.S. Al-Janabi, Extraction of cobalt(II) from aqueous solution by $\mathrm{N}, \mathrm{N}^{\prime}$-carbonyl difatty amides. Chinese Chemical Letters, 2011, 22 (4): 469-472. 
[23] L. Zhao, S. Zhong, and K. Fang, Determination of cadmium(II), cobalt(II), nickel(II), lead(II), zinc(II), and copper(II) in water samples using dual-cloud point extraction and inductively coupled plasma emission spectrometry. Journal of Hazardous Materials, 2012, 239: 206-212.

[24] S. Abbas, Y. Al-Khafaji, and H. Al-Khafaji, Cloud Point Extraction as a Procedure of Separation and Pre-Concentration for Cupper (II) Determination Using Spectrofluorometric Techniques. Journal of Pharmaceutical Sciences and Research, 2018, 10 (7): 1748-1752.

[25] H. Xu, W. Zhanga, X. Zhangb, et al., Simultaneous preconcentration of cobalt, nickel and copper in water samples by cloud point extraction method and their determination by flame atomic absorption spectrometry. Procedia Environmental Sciences, 2013, 18: 258-263.

[26] F. Liu, J. Sun, and B. Jiang, Use of cloud point extraction for removal of nanosized copper oxide from wastewater. Chinese Science Bulletin, 2010, 55: 346-349.

[27] J.K. Shawket, M.U. Kadhium, and A.S. Alwan, Incorporation solvation with cloud point extraction method for separation and spectrophotometric determination of Cerium(III). Orienal Journal of Chemistry, 2017, 33(4): 1985-1993.

[28] S.K. Jawad, M.O. Kadhim, and E.A. Azooz, Incorporation onium system with cloud point extraction method for extraction and determination Iron(III) and Mercury(II) in different samples, Orienal Journal of Chemistry, 2017, 33(4): 1879-1889.

[29] M.M. Radhi, A.I. Ibrahim, and I.A. Mizher, Electrochemical characterization of sky honey mediated by glassy carbon electrode modified with carbon nanotube. Nano Biomedicine and Engineering, 10 (4), 417-422.

[30] S.K. Jawad, E.A. Azooz, Cloud point extraction for separation, preconcentration and extraction of Nickel(II) as chloroanion by use crown ether DB18C6 coupled with spectrophotometric determination, International Journal of Scientific and Technology Research, 2014, 4(32): 1723.

[31] A. Arain, T. GulKazi, and I. Afridi, A new dispersive liquid-liquid micro extraction using ionic liquid based microemulsion coupled with cloud point extraction for determination of copper in serum and water samples, Ecotoxicology and Environmental Safety, 2016, 126: 186192.

[32] F.A. Wannas, S.K. Jawad, Extraction and determination of Nickel(II) via cloud point method. Inter. Journal of Engineering Technology, 2018, 7(4): 725-731.

[33] S.K. Jawad, M.U. Kadhium, and E.A. Azooz, Application cloud point extraction method joined with liquid Ion exchange for selective determination of $\mathrm{Fe}^{3+}$ and $\mathrm{Hg}^{2+}$ in real samples. Journal of Engineering and Applied Sciences, 2019, 14(11): 3514-3521.

[34] A. Lemos, S. Santos, and X. Baliza, Me-BTABr reagent in cloud point extraction for spectrometric determination of copper in water samples. Journal of the Brazilian Chemical Society, 2006, 17(1): 30-35.

[35] J. Chen, K. Teo, Determination of cadmium, copper, lead and zinc in water samples by flame atomic absorption spectrometry after cloud point extraction. Analytica Chimica Acta, 2001, 450(215): 215-222.

[36] L. Manzoori, B. Tabrizi, The application of cloud point preconcentration for the determination of $\mathrm{Cu}$ in real samples by flame atomic absorption spectrometry. Microchemical Journal, 2002, 72(1): 1-7.

[37] A. Tang, D. Jiang, Cloud point extraction preconcentration for capillary electrophoresis of metal ions. Analytica Chimica Acta, 2004, 507(203): 199-204.

[38] M. Silva, A. Frescura, Determination of trace elements in water samples by ultrasonic nebulization inductively coupled plasma mass spectrometry after cloud point extraction. Spectrochimica Acta Part B: Atomic Spectroscopy, 2000, 55: 803.

[39] M. Shokrollahi, S. Ghaedi, Cloud point extraction for the determination of copper in environmental samples by flame Atomic sbsorption spectrometry. Quimica Nova, 2008, 31(1): 70-74.

[40] N. Baghban, A. Shabani, and S. Dadfarnia, Cloud point extraction of trace amounts of copper and its determination by flow injection flame atomic absorption spectrometry. Croatica Chemica Acta, 20102, 85(1): 8590.

[41] M. Ghaedi, A. Shokrollahi, F. Ahmadia, Cloud point extraction for the determination of copper, nickel and cobalt ions in environmental samples by flame atomic absorption spectrometry. Journal of Hazardous Materials, 2008, 150: 533-540.

[42] V. Lemos, M. Santos, and G. David, Development of a cloud-point extraction method for copper and nickel determination in food samples. Journal of Hazardous Materials, 2008, 159: 245-251.

[43] M. Ghaedi, A. Niknamb, and E. Niknama, Development of efficient method for preconcentration and determination of Copper, Nickel, Zinc and Iron ions in environmental samples by combination of cloud point extraction and flame atomic absorption spectrometry. Central European Journal of Chemistry, 2009, 7(1): 148-154.

[44] P. Biparva, M. Hadjmohammadi, Cloud point extraction using NDTT reagent for preconcentration and determination of copper in some environmental water Samples by flame atomic absorption spectroscopy. Acta Chimica Slovenica, 2007, 54: 805-810.

Copyright $\odot$ Ebaa Adnan Azooz, Jihan Razzaq Moslim, Safa Mageed Hameed, Shawket Kadhem Jawad, and Emad Abbas Jaffar Al-Mulla. This is an open-access article distributed under the terms of the Creative Commons Attribution License, which permits unrestricted use, distribution, and reproduction in any medium, provided the original author and source are credited. 